\title{
Analytical Modelling of an Urban Water Distribution and Management System and its Implementation
}

\author{
Edwin Joy $^{1}$, Nitish Kumar ${ }^{2}$, Divyansh Bhageria ${ }^{3}$, Shruti Avinash Ghorpade ${ }^{4}$ and Bikash Sharma ${ }^{5}$ \\ ${ }^{1-5}$ Department of Electronics \& Communication Engineering
}

Sikkim Manipal Institute of Technology, Sikkim Manipal University

\begin{abstract}
The rapid increase of population and urbanization has led to weak management of water resources along with compromised quality of water. In this work, we discuss the modelling and simulation of water distribution systems right from the mathematical model to realizing the system in large scale. We explore various ways of simulating the system using MATLAB $®$ and Simulink ${ }^{\circledR}$. Initially, the work deals with developing a simulation environment for the system which progresses on to the incorporation of a control system. The simulation gives a good overview of the dynamics of the system. A bang-bang controller-based control system is included to demonstrate the feasibility of the simulation.
\end{abstract}

Keywords : Analytical model, urban water distribution system, MATLAB, Simulink, bang-bang controller

\section{INTRODUCTION}

Water being the primary element for the sustenance of all living organisms is not abundant and hence proper planning of water usage is imperative. The complexity of water distribution systems can escalate very quickly as the forcing elements and nodes increase. Keeping track of changes in each reservoir becomes difficult as the fluid flow is inter-dependent. Due to our negligence, water scarcity is of notable concern with the accelerated population growth leading to lack of proper management $[1,2]$. The water supply chain is hindered due to unregulated water system i.e., due to overflow and underflow. All these factors and the constant degradation of ground water demands sustainable usage of water [3, 4].

Water management systems have proven to curb water wastage and save electricity [5, 6]. As the number of reservoirs and forcing elements increase, modelling becomes more challenging, and one is forced to take a more heuristic decision for proper distribution of water. This leads to frequent overflow and thus not an efficient way to tackle the problem.

To overcome the above stated problems, this paper provides a way to model, simulate and monitor such systems [7,8] taking advantage of MATLAB and Simulink ecosystem. A Simulink model with live tracking of water level in the tank is built, to get constant updates about water level, and this prevents tank overflow and underflow conditions. Optimization and control of distribution system can be done by integrating MATLAB function blocks or Stateflow charts.

The simulation methodology can be adopted for any water management, control and optimization related projects.

\section{METHODOLOGY}

A mathematical model $[9,10]$ is first developed for the system using known parameters. It has been realized that the height of the tank is dependent on the usage pattern and the amount of water pumped along with the valve settings. The resulting model is then used to develop the algorithm for the simulation program. The simulation is designed using MATLAB and Simulink to incorporate the mathematical model. This model is then improved upon to inculcate control over the system using MATLAB Stateflow Charts. A brief overview of the model is shown in Fig. 1. The input signals determine the output of the system which is controlled by the control in the feedback loop $[9,10]$. 


\section{International Advanced Research Journal in Science, Engineering and Technology}

Vol. 8, Issue 9, September 2021

DOI: 10.17148/IARJSET.2021.8969

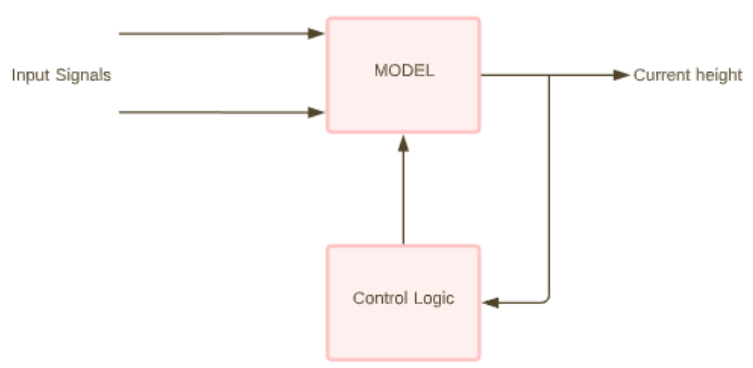

Fig. 1. System Modelling

The model designed in MATLAB which results out to a model of single tank system and is finally summed up to a model of three tank system, each tank has its own valve to control water flow intensity. Real time valve control and motor control are also incorporated.

\section{MODELLING}

The amount of water left in the tank at time $t$ is a function of the amount of water used per unit time $g(t)$ and the amount of water pumped into the tank per unit time $y(t)$. These two information serves as main inputs to the model bearing units litres/second. $\mathrm{R}$ denotes the valve setting. It takes value between 0 and 1 . The tanks are considered to be cylindrical. Let $\mathrm{r}$ be the radius of the tank in meters. $\mathrm{h}(\mathrm{t})$ is the height of water in the tank at time $\mathrm{t}$.

For a small increment in time dt,

$$
\begin{gathered}
{[\operatorname{Rry}(t)-g(t)] d t=\pi r^{2} d h \times 1000 \text { litres }} \\
d h=\frac{[\operatorname{Rry}(t)-g(t)] d t}{\pi r^{2} \times 1000} \\
h(t)=h_{0}+\int_{0}^{t} \frac{[\operatorname{Rry}(t)-g(t)] d t}{\pi r^{2} \times 1000}
\end{gathered}
$$

Where $\mathrm{h}_{0}$ is the initial height of water in the tank. Simulating a single tank requires $\mathrm{y}(\mathrm{t})$ and $\mathrm{g}(\mathrm{t})$ as inputs and are subjected to other constant parameters of tank and valve.

The water usage profile for a single person is approximated by observing daily activities. The graph is normalized such that the total water usage amounts to about 350 litres a day. The data points are at a 30 minutes interval. The data is interpolated to include data for every second. Fig. 2 shows the approximated data curve. This graph is then randomized by convolution with the Gaussian function, superposed with itself for a required number of people.

Similarly, forcing element profile is also made considering the amount of water pushed every second and the on/off times. Fig. 3 shows the data curve for the forcing element profile. The usage profile and forcing element profiles are parameters to the tank object which gives the current height of the tank as output.

The various discrete entities in the system are modelled using MATLAB function blocks or Simulink System Blocks. The MATLAB script is written to inculcate the dynamics of these entities.

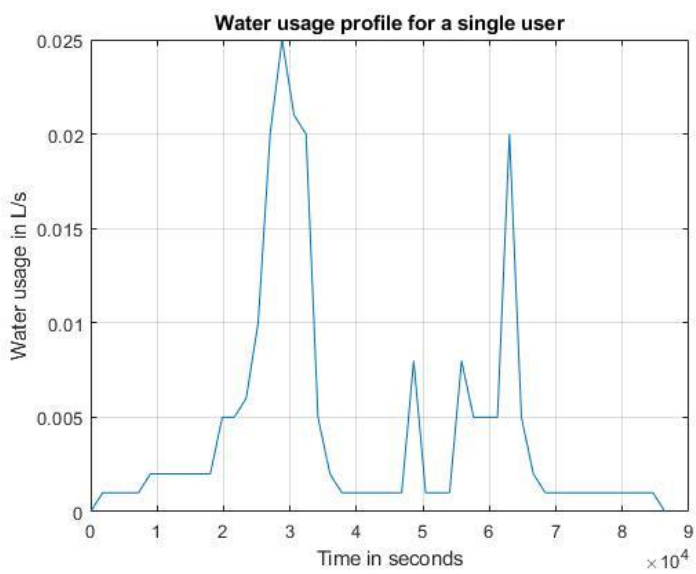

Fig. 2. Water usage profile 
Vol. 8, Issue 9, September 2021

DOI: 10.17148/IARJSET.2021.8969

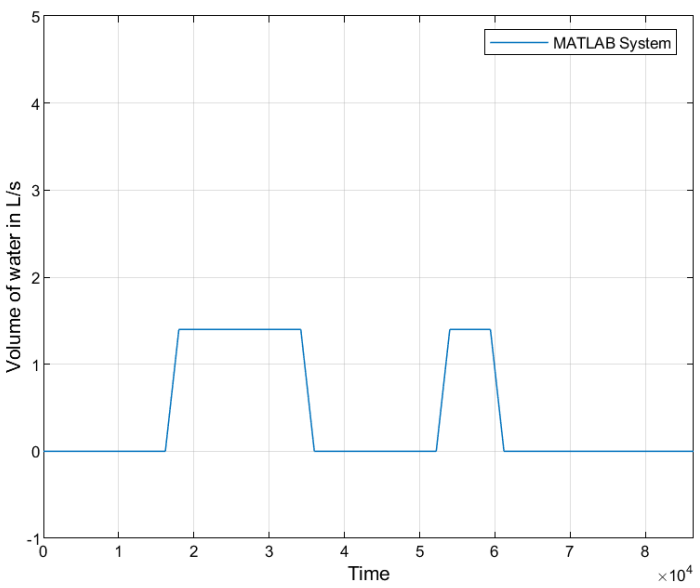

Fig. 3. Forcing element profile

\section{IMPLEMENTING THE MODEL IN SIMULINK}

Simulink was chosen for modelling the system. The system model is based on the mathematical model arrived above. Simulink is a versatile development environment which has a block architecture. Blocks are linked logically giving a graphical representation of the entire system. Modelling was attempted through two different ways. They are discussed in this section.

\subsection{Using MATLAB Function blocks:}

These blocks represent functions in the MATLAB language [11]. They are very simple to code and understand. The downside of this approach is that it does not facilitate reusability. This method also clutters the model and hence makes it difficult to manage in larger models. The model created using this approach for a single tank system is given (Fig. 4).

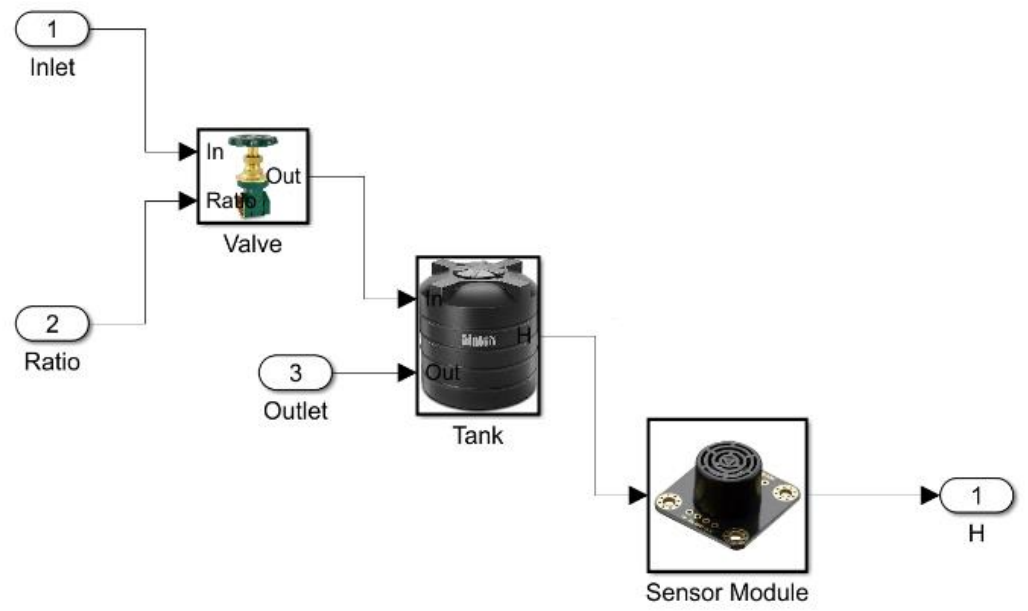

Fig. 4. Modelling a single tank system using function blocks

The parameters for each block are loaded to the MATLAB workspace. This becomes very hard to manage as the number of entities for simulation increases.

Using this method, a system of three tanks is given in Fig. 5. 


\section{International Advanced Research Journal in Science, Engineering and Technology}

Vol. 8, Issue 9, September 2021

DOI: $10.17148 /$ IARJSET.2021.8969

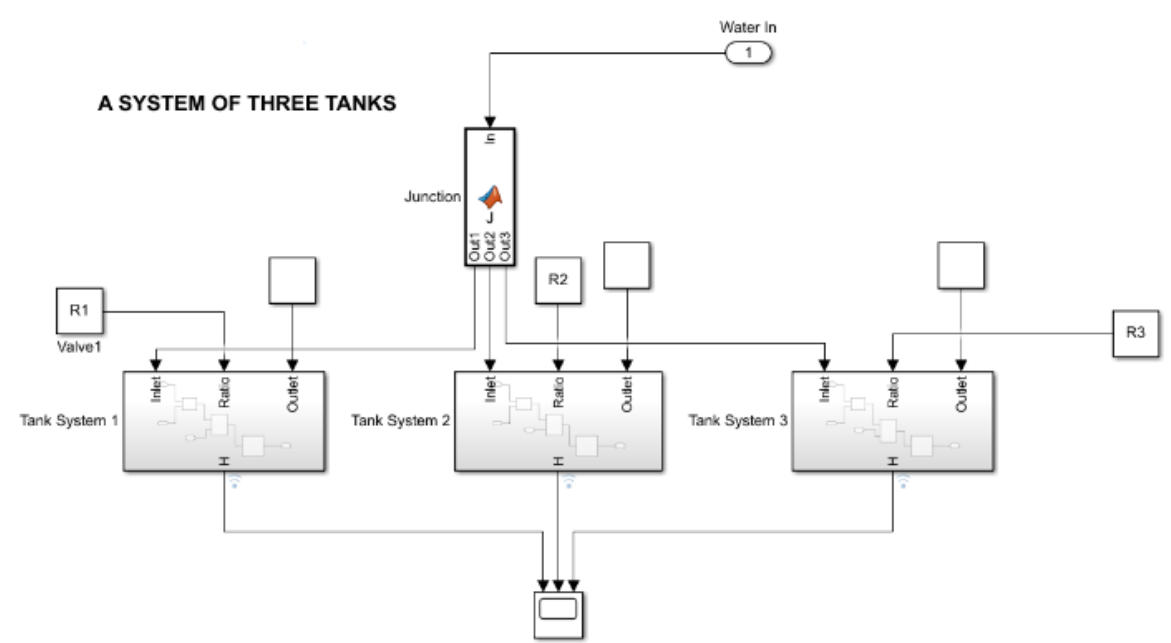

Fig. 5. Modelling a three-tank system using function block

\subsection{Using MATLAB \& Simulink System Blocks:}

These are instances of classes inherited from the MATLAB System class [12]. System classes provide an interface between the user and the MATLAB system. It helps to create user defined blocks helping us achieve a great deal of customization. Blocks can be reused and model clutter is greatly reduced. The model created using this approach is given in Fig. 6. We can see that the model looks cleaner and easier to comprehend while using a system object. Using this model, a system of three tanks is given in Fig. 7.

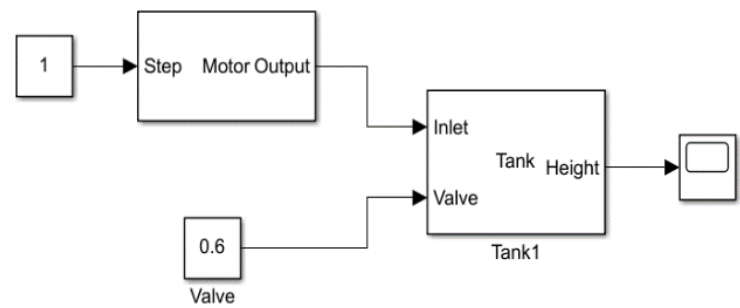

Fig. 6. Modelling a tank system using Simulink System Blocks

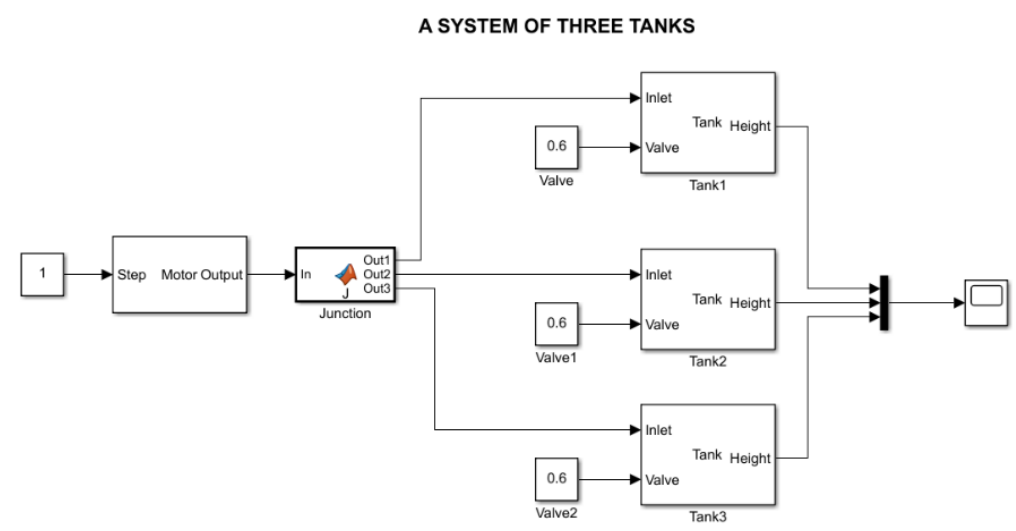

Fig. 7. Modelling a three-tank system using Simulink System Blocks

System blocks uses an object-oriented approach to modelling blocks. They are more versatile and contains all the essence of object-oriented programming. The initial modelling began with the MATLAB function blocks. The model wasted updated with the introduction of system blocks. The advantages of MATLAB system blocks are given below: 


\section{International Advanced Research Journal in Science, Engineering and Technology}

Vol. 8, Issue 9, September 2021

DOI: $10.17148 /$ IARJSET.2021.8969

- $\quad$ The system blocks can be run in pre-compiled mode where MATLAB converts the code to C++ code. This boosts simulation speed

- $\quad$ System blocks can be reused and parametrized

- It gives flexibility in configuring simulation settings of a block

- $\quad$ The code is more centralized and model clutter is reduced

\subsection{Modeling Elements}

Following are the elements modelled using MATLAB System blocks

- Tanks/reservoirs:

This block captures the dynamics of a tank. The population, initial height of water and dimensions of the tank are taken as parameters of the tank (Fig. 8)

The unit usage profile is loaded to the model. The constructor of the tank object randomizes the unit usage, superposes the data for the given population and array is interpolated for each second. (Fig. 8b)

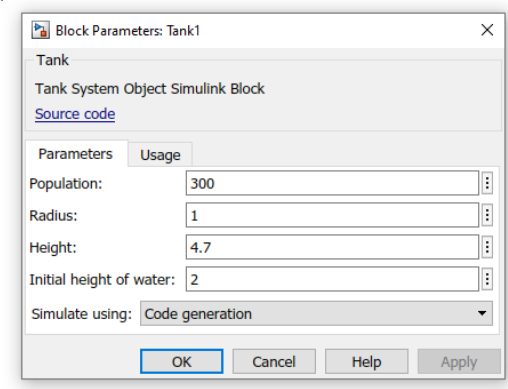

Fig. 8a. Tank model parameters

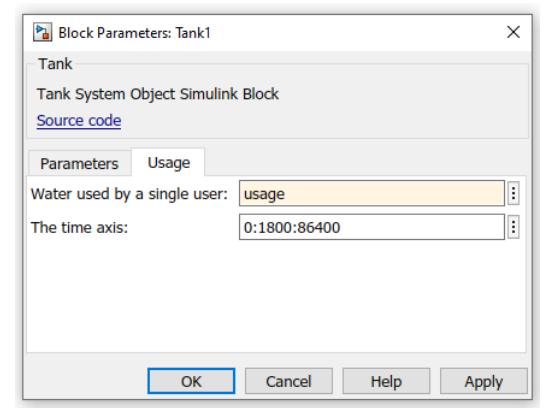

Fig. 8b. Tank model parameters

Fig. 7 shows that the tank object takes valve as an input. The valve is normalized between 0 and $1-0$ representing that the valve is fully closed, 1 representing that the valve is fully open.

- $\quad$ Motors/forcing elements:

The motor block generates its profile by using the parameters given in Fig. 9. The data is interpolated so that data exists every second.

Other simple blocks like junctions are modelled using function blocks.

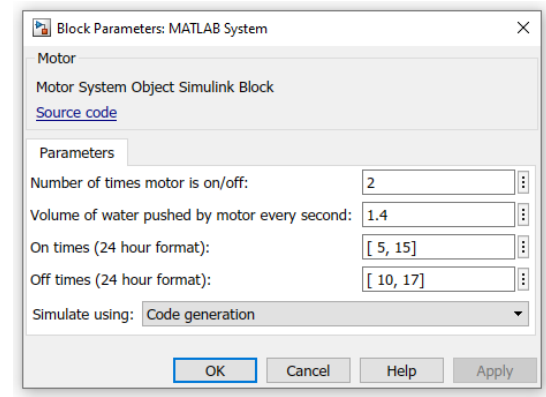

Fig. 9. Motor model parameters 


\section{International Advanced Research Journal in Science, Engineering and Technology}

Vol. 8, Issue 9, September 2021

DOI: 10.17148/IARJSET.2021.8969

\section{SIMULATION}

The simulation is run for a single tank system for a single day (86400 seconds). The system is currently an open loop system with no control. The height vs time graph is plotted (Fig. 10)

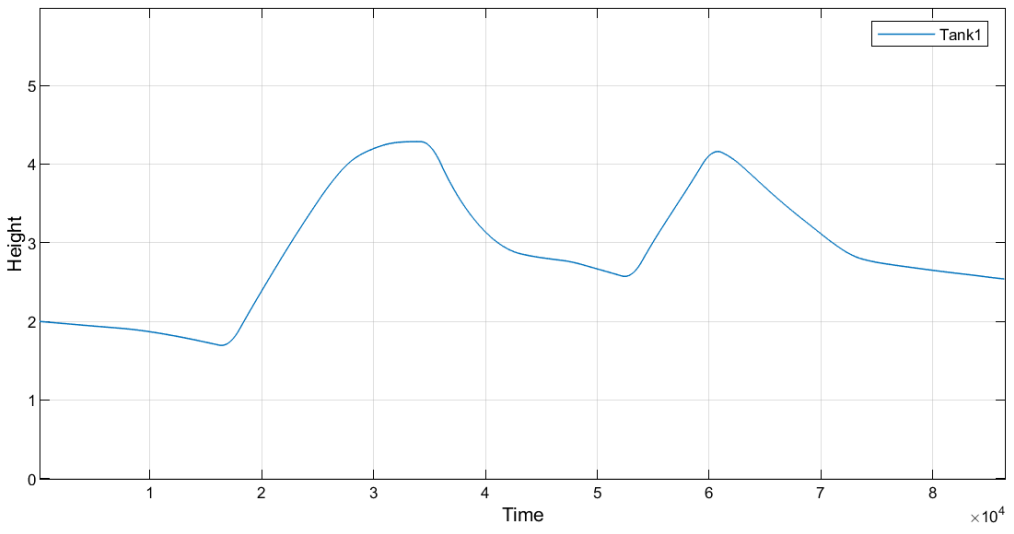

Fig. 10. Height of water in the tank

We can now simulate three tank system using the same method. The graph is plotted (Fig. 11). The motor is turned on twice a day. The points where the motor can be understood from the plot.

The output is updated every second through the day. We can see that the output greatly depends on the initial height of the tank. Using this basic model, we can add more functionalities like pressure distribution at junctions and valves, control and logic. In a case with lot of tanks with a single forcing element, an optimal valve setting can be found by using an optimization algorithm.

We can also integrate algorithms which optimizes the power consumption.

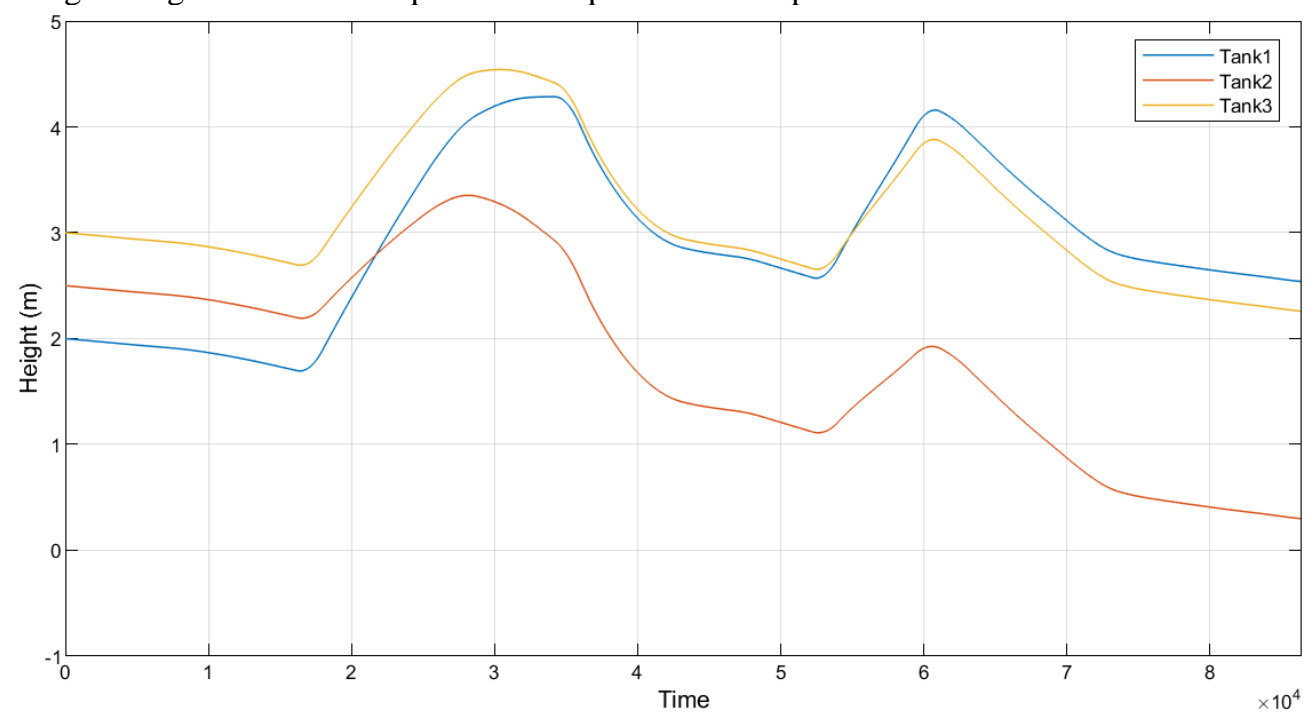

Fig. 11. Height of water of a three-tank system

\section{ESTABLISHING CONTROL LOGIC}

Control logic of this system can be easily established using MATLAB Stateflow[13]. This is a very intuitive way to model a system logic providing a state diagram. A bang-bang control system [9, 10] is demonstrated (Fig. 12a). The valve is controlled via feedback from the Logic subsystem (Fig. 12b). The logic system detects if the motor is on/off from the slope of the height function. Using the slope, the Stateflow diagram (Fig. 12c) finds the time that will take for overflow or underflow of the tank and provides appropriate valve setting. A dashboard is set up for motor state indication and valve knob. 


\section{International Advanced Research Journal in Science, Engineering and Technology}

Vol. 8, Issue 9, September 2021

DOI: 10.17148/IARJSET.2021.8969

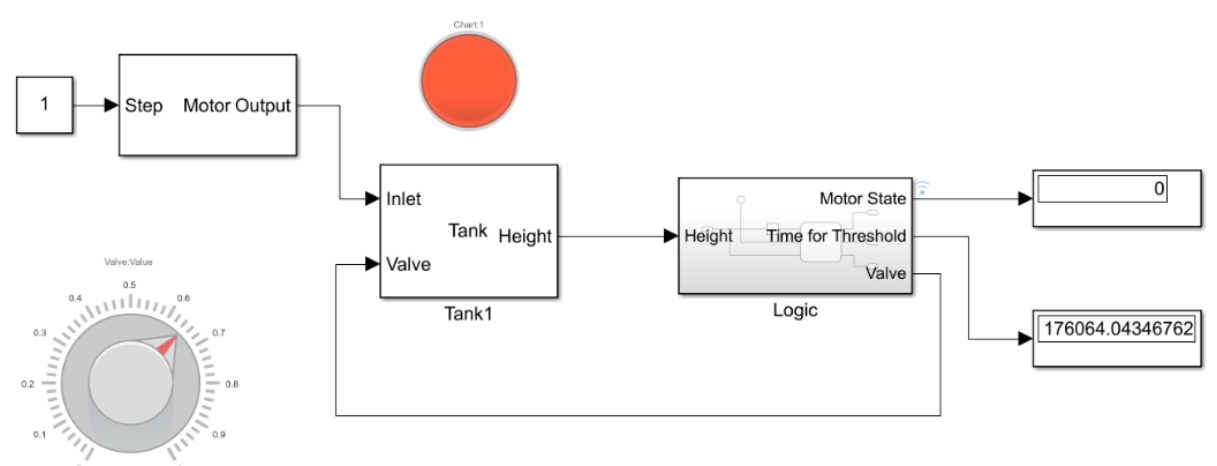

Fig. 12a. Tank system with real time valve control

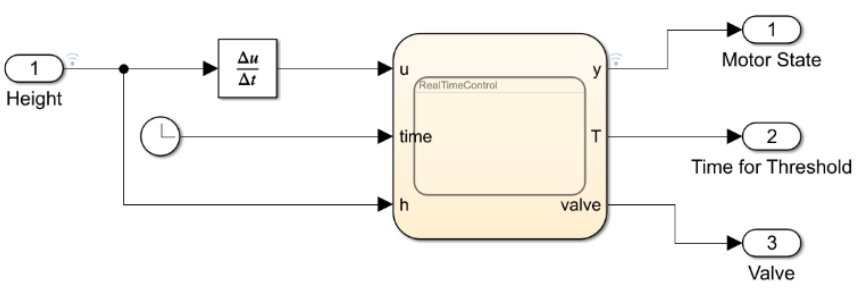

Fig. 12b. Logic subsystem

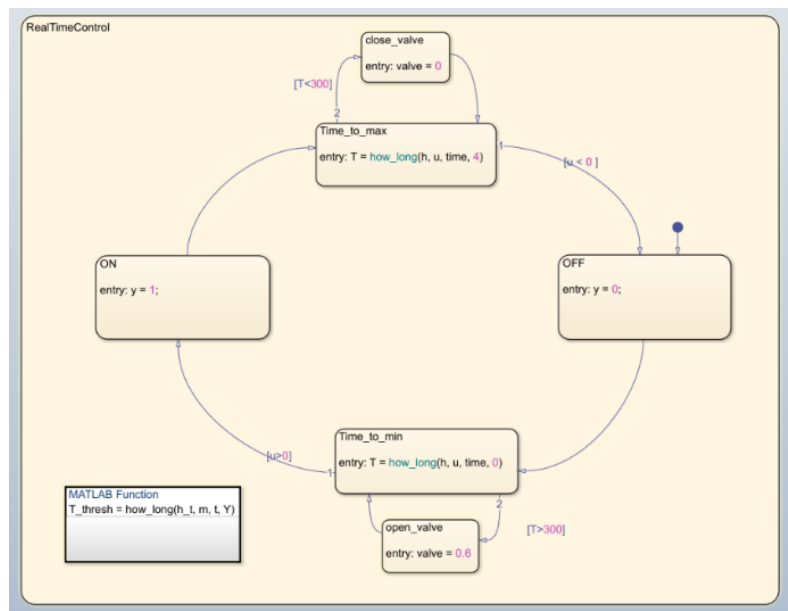

Fig. 12c. Logic state diagram

\section{CONCLUSION}

Simulation Of Water management system helps us plan a better control system especially when the population is large. The simulation screenshots denote the scalability of the model and help run more advanced algorithms and control system architectures like SCADA [14]. The bang-bang controller can be modified to more robust controllers for time critical applications. Simulation for IoT implementation of water distribution systems is a challenge in urban areas [15] and development can be accelerated via simulation of such systems.

Simulation of systems also helps in pin-pointing all the variables while implementing the design. This methodology can be used to add more sophisticated systems like Hardware-in-Loop (HIL). The height data can be directly acquired from an FPGA based system and be computed in the Simulink environment.

A very simple control logic was simulated. More mission critical applications would require actuator dynamics to be incorporated. Various optimization can be performed to find the best valve settings or motor on/off times to save electricity and water. Machine Learning or constrained optimization techniques can be used for parameter optimizations. 


\section{International Advanced Research Journal in Science, Engineering and Technology}

Vol. 8, Issue 9, September 2021

DOI: 10.17148/IARJSET.2021.8969

\section{ACKNOWLEDGEMENT}

This work was supported by Sikkim Manipal University under TMA Pai University Research Fund (Minor Grant) vide ref.: 6100/SMIT/R\&D/ Project/11/2018 dated: 18/12/2018. Authors would like to thank Sikkim Manipal Institute of Technology, Sikkim Manipal University for the support.

\section{REFERENCES}

[1] William J. Cosgrove and Daniel P. Loucks. Water management: Current and future challenges and research directions. Agu Publications, 28 June 2014

[2] "4 Smart Water Management in Cities", ITU-T Focus Group on Smart Sustainable Cities, 2014.

[3] Kavita Wankhade, Krishnachandran Balakrishnan, Vishnu M.J. Urban Water Supply \& Sanitization in India, IIHS RF Paper on Water Supply and Sanitation

[4] Benedetti, L., Langeveld, J., Comeau, A., Corominas, L., Daigger, G., Martin, C., Mikkelsen, P. S., Vezzaro, L., Weijers, S. \& Vanrolleghem, P. A. Modelling and monitoring of integrated urban wastewater systems: review on status and perspectives. Water Science and Technology 68 (6), 1203-1215.

[5] O. Oyedele Adeosun, Obafemi Awolowo University. Water Distribution System Challenges and Solutions

https://www.wateronline.com/doc/water-distribution-system-challenges-and-solutions-0001

[6] Mr. Prashant Palkar, Shrinivas Patil, Pooja Belagali, Mr. Ashish Chougule. Automation in drinking water supply distributed system and testing of water, IOSR Journal of Electronics \& Communication Engineering (IOSR-JECE)

[7] Dragan Savic: A Smart City Without Smart Water Is Only a Pipe Dream, Proceedings of the 37th IAHR World Congress August 13 - 18, 2017, Kuala Lumpur, Malaysia

[8] Gustaf Olsson. Urban Water Supply Automation - Today and Tomorrow. Journal of Water Supply: Research and Technology.

[9] Benjamin Kuo, F. Golnaraghi. Automatic Control Systems, $9^{\text {th }}$ Edition. USA: Wiley, John Wiley \& Sons, Inc., 2010

[10] I. J Nagrath, M. Gopal. Control Systems Engineering, $4^{\text {th }}$ Edition, New Delhi, India: New Age International Publishers, 2006

[11] Rudra Pratap. Getting Started with MATLAB - A Quick Introduction for Scientists and Engineers, $7^{\text {th }}$ Edition, New Delhi, India: Oxford University Press, 2019

[12] MathWorks, (2020): System Blocks: Documentation (R2020b). Retrieved from

https://www.mathworks.com/help/simulink/ug/what-is-matlab-system-block.html

[13] MathWorks, (2012). Stateflow ${ }^{\mathrm{TM}}$ : Documentation (R2020b). Retrieved from

https://www.mathworks.com/help/stateflow/

[14] Pratiksha Hattikatti, Savita Karwande, Mrunalini Bhandarkar: "PLC Controlled Water Distribution Plant", International Journal of Research in Engineering \& Advanced Technology (IJREAT), Volume 2, Issue 1, 5 May, 2015

[15] Rakib Ahemed, Mahfida Amjad. “Automated Water Management System (WMS)”. I.J. Education and Management Engineering, $2019,27-36$. 